\title{
REVIEW
}

\section{Inducible resistance to Fas-mediated apoptosis in B cells}

\author{
Rothstein Thomas L \\ Departments of Medicine and Microbiology, and the Evans \\ Memorial Department of Clinical Research, Boston University \\ Medical Center, Boston, MA, USA
}

\begin{abstract}
Apoptosis produced in B cells through Fas (APO-1, CD95) triggering is regulated by signals derived from other surface receptors: CD40 engagement produces upregulation of Fas expression and marked susceptibility to Fas-induced cell death, whereas antigen receptor engagement, or IL-4R engagement, inhibits Fas killing and in so doing induces a state of Fas-resistance, even in otherwise sensitive, CD40stimulated targets. Surface immunoglobulin and IL-4R utilize at least partially distinct pathways to produce Fas-resistance that differentially depend on PKC and STAT6, respectively. Further, surface immunoglobulin signaling for inducible Fas-resistance bypasses Btk, requires NF- $\kappa \mathrm{B}$, and entails new macromolecular synthesis. Terminal effectors of $\mathrm{B}$ cell Fas-resistance include the known anti-apoptotic gene products, Bcl-xL and FLIP, and a novel anti-apoptotic gene that encodes FAIM (Fas Apoptosis Inhibitory Molecule). faim was identified by differential display and exists in two alter-
\end{abstract}

\footnotetext{
Abbreviations: AICD, activation-induced cell death; ALPS, autoimmune lymphoproliferation syndrome; CARD, caspase recruitment domain; CK, casein kinase; CMC, cell-mediated cytotoxicity; DISC, death-inducing signaling complex; EST, expressed sequence tag; FADD, Fas-associating protein with death domain; FAIM, Fas apoptosis inhibitory molecule; FISH, fluorescence in situ hybridization; FLICE, FADD-like ICE; FLIP, FLICE inhibitory protein; HEL, hen egg lysozyme; ICE, interleukin-1 $\beta$-converting enzyme; IFN, interferon; KO, knock-out; LPS, lipopolysaccharide; PARP, poly-ADP ribose polymerase; PCR, polymerase chain reaction; $\mathrm{PH}$, pleckstrin homology; PKC, protein kinase C; PMA, phorbol myristate acetate; RT, reverse transcription; TNFR, tumor necrosis factor receptor

* Correspondence to: Thomas L. Rothstein, Immunobiology Unit, Department of Medicine, EBRC-437, Boston Medical Center, 650 Albany Street, Boston, MA 02118 USA

Fax: 617-638-7140, E-mail: trothstein@med-med1.bu.edu
} 
Inducible Fas-resistance in B cells

natively spliced forms; faim-S is broadly expressed, but faim-L expression is tissue-specific. The FAIM sequence is highly evolutionarily conserved, suggesting an important role for this molecule throughout phylogeny. Inducible resistance to Fas killing is hypothesized to protect foreign antigen-specific B cells during potentially hazardous interactions with FasLbearing $\mathrm{T}$ cells, whereas autoreactive $\mathrm{B}$ cells fail to become Fas-resistant and are deleted via Fas-dependent cytotoxicity. Inadvertent or aberrant acquisition of Fas-resistance may permit autoreactive B cells to escape Fas deletion, and malignant lymphocytes to impede anti-tumor immunity.

key words: Apoptosis, Fas, B lymphocytes, FAIM, FLIP, Bcl$\mathrm{x}_{L}$,surface immunoglobulin, IL-4R, CD40, autoreactivity.

\section{INRODUCTION}

Fas/APO-1 (CD95) is a death receptor of the TNF receptor (TNFR) family, and shares with death receptors TNFR1, DR3 (TRAMP, Wsl, APO-3), DR4 (TRAIL-R1) and DR5 (TRAIL-R2) extracellular cysteine-rich pseudorepeats, intracellular C-terminal death domains, and reliance on FADD as a critical early mediator of signaling for cell death (although FADD-dependence has been questioned for DR4)[1-7]. The cognate ligand for Fas (FasL) is an activation antigen expressed by CD4+ Th1 effector cells and CD8 cytotoxic $\mathrm{T}$ lymphocytes, (although its activity in the latter is frequently masked by the more substantial destructive power of the perforin-granzyme system), as well as natural killer cells[8-13]. The congenital loss of Fas (as in lpr/lpr mice and Fas null mice, and in human Autoimmune Lymphoproliferation Syndrome) or of its ligand (as in gld/gld mice) is accompanied by severely elevated levels of serum autoantibodies associated with frank autoimmunity[14-24]; for this reason Fas is thought to play a key role in the regulation of $\mathrm{B}$ cells, particularly in the regulation of autoreactive $\mathrm{B}$ cells. These observations are supported and refined by additional experiments, carried out over the last dozen years, that more clearly document abnormal B cell function in Fas-deficient animals and distinguish $\mathrm{B}$ cell defects from abnormalities in the $\mathrm{T}$ cell population. Thus, in both mixed radiation chimeras and tetraparental chimeras, autoimmune immunoglobulin was derived solely from lpr B cells and not from co-existing phenotypically normal B cells that were simultaneously exposed to abnormal lpr T cells [25-27]. Moreover, autoantibody production was present and undiminished when Fas deficiency was restricted to $B$ cells through production of transgenic MRL- lpr mice 
that express Fas within the thymocyte and peripheral $\mathrm{T}$ cell populations by use of the murine lck promoter, in comparison to unmanipulated MRL-lpr mice[28]. These results indicate that a block in the Fas death pathway leads to dysregulation of B cells that express self-recognizing specificities, suggesting that under normal circumstance Fas functions to delete such autoreactive B cells.

In lpr and Fas null B cells, Fas-induced cell death is blocked congenitally by loss of surface Fas expression. However, this is a somewhat artificial, certainly nonphysiological, way of thwarting Fas killing. In view of the very severe immune dyscrasias attendant to genetic interference with Fas signaling for cell death, the question arose as to whether Fas-mediated cell death is ever blocked during normal immune cell activity, because if that would happen, it might contribute to autoimmune B cell activity. More generally, it was unclear to what extent the outcome of Fas signaling is modulated by other influences, particularly receptor-specific ones. Although it was known that B cell activation, as with lipopolysaccharide, was associated with Fas expression and sensitivity to Fas signaling for cell death that greatly exceed the low levels present in naive B cells[29-33], we pursued this issue further, by evaluating the effect of triggering certain surface receptors in primary B cells. Early on it was found that B cell stimulation through CD40 for 1-3 d markedly upregulated both surface Fas expression, and sensitivity to Fas-mediated apoptosis. In direct contrast, B cell stimulation through surface immunoglobulin (sIg) failed to enhance susceptibility to Fas killing at all. Thus, these two mitogenic receptor- mediated signals differ markedly in their capacity to increase the sensitivity of B cell targets to Fas-mediated apoptosis[34].

We then evaluated whether the failure of sIg engagement to induce Fas-sensitivity resulted from a passive process, due to inadequate signaling for this outcome, or a dominant process, due to active suppression of cytotoxicity. To address this issue, primary B cells were stimulated with CD40L in combination with, or sequentially with, anti-Ig, and then examined for susceptibility to apoptosis in the form of FasL-dependent Th1-cell mediated cytotoxicity (Th1-CMC). B cells stimulated by CD40L plus antiIg expressed increased levels of surface Fas comparable in magnitude to the elevated levels present in B cells stimulated by CD40L alone; however, the susceptibility of dualstimulated B cells to Fas-mediated apoptosis was much reduced in comparison to B cells stimulated only by CD40L[34], [35]. Whereas the percent specific lysis produced during a $4 \mathrm{~h}{ }^{51} \mathrm{Cr}$ release assay of $\mathrm{B}$ cells stimulated by CD40L alone typically ranged from 40-60 \% at the highest Th1 effector: B cell target ratio tested (9:1), the corresponding percent specific lysis for B cells stimulated by both CD40L and anti-Ig was only 0-15\%. Considering a large number of experiments, the mean level of protection against Fas killing produced by sIg signaling amounted to more than 20 -fold, meaning that a greater than 20-fold higher Th1 effector: B cell target ratio was needed to produce comparable levels of apoptosis in B cells stimulated by the combination of CD40L plus anti-Ig as in B cells stimulated by CD40L alone[35]. Thus, anti-Ig-induced sIg crosslinking established a state of resistance to Fas-mediated apoptosis, or Fas-resistance. Moreover, sIg 
Inducible Fas-resistance in B cells

engagement by specific antigen similarly produced Fas-resistance, in experiments in which B cells were obtained from transgenic animals expressing either B cell receptors that recognize $\mathrm{H}-2 \mathrm{~K}^{k, b}$, or $\mathrm{B}$ cell receptors that recognize HEL, demonstrating that sIginduced Fas-resistance is a physiologic process and is not dependent on the use of crosslinking anti-Ig antibody[34],[36].

The opposing effects of CD40 and sIg engagement on Fas signaling for cell death raised the question of whether engagement of other surface receptors might similarly alter susceptibility to Fas-mediated apoptosis. To address this issue, various ligands were tested in conjunction with CD40L stimulation prior to evaluating sensitivity to Th1 cell-mediated cytotoxicity. Through this effort IL-4, alone among the cytokines examined, was found to produce Fas-resistance[37]. As with anti-Ig, IL-4 produced Fasresistance when added either concurrently, or sequentially, with CD40L, and did so without any change in the elevated level of Fas expression produced by CD40 signaling; however, IL-4 in optimal doses was less effective than anti-Ig, providing a level of protection against Fas-mediated apoptosis that averaged about 10-fold[37].

These results with anti-Ig and IL-4 indicate that in normal B cells, Fas-mediated apoptosis can be suppressed through inducible receptor-triggered mechanisms completely distinct from genetic alteration of Fas. This paradigm is supported by subsequent reports of in vitro experiments in the human system, and of in vivo experiments in the murine system[38-41]. Thus, the outcome of B cell stimulation with respect to Fas signaling is regulated on the basis of particular environmental cues as interpreted by specific receptor binding.

In the experiments described above, Fas-mediated apoptosis was initiated by Th1 cell membrane-bound FasL, and Fas-resistance was observed in B cells stimulated by CD40L plus anti-Ig, or by CD40L plus IL-4. Similar results were obtained with recombinant, soluble FasL[35]. Surprisingly though, a different outcome appeared when Fas killing was triggered by soluble Jo-2 monoclonal anti-Fas antibody, in which case the level of protection against Fas-mediated apoptosis was much reduced in comparison to that which was apparent with Th1 effector cells, to the point that Fas-resistance was not always evident. The failure to observe Fas-resistance in antibody-treated B cells suggests that Jo-2 produces a super-physiological stimulus that overwhelms receptordriven Fas-resistance. The reason for this might be that B cell FcR crosslinking of whole anti-Fas antibody produces more efficient Fas engagement, inasmuch as Jo-2induced Fas killing was blocked by $2.4 \mathrm{G} 2$ anti-FcR antibody, or it might be that the anti-Fas antibody binds an epitope distinct from that engaged by FasL, inasmuch as soluble FasL did not block the ability of Jo-2 to produce apoptosis in Fas-resistant B cells treated with CD40L plus anti-Ig[35] (and unpublished results). Regardless of the mechanism, however, the results with Jo-2 indicate that sIg- and IL-4R-induced protection against Fas-mediated apoptosis is relative rather than absolute, and can be overcome by especially strong apoptotic signals derived from Fas, including those produced by particularly high Th1 effector cell: B cell target cell ratios. 
Rothstein TL

\section{Receptor signaling for Fas-resistance}

Although the outcomes of engaging sIg and IL-4R in terms of inducible resistance to Fas-mediated apoptosis are similar, the pathways utilized to bring this about differ, as evidenced by the reliance of Fas-resistance induction on specific signaling mediators. Thus, inhibition of PKC by cell-permeant H7, or depletion of PKC by prolonged exposure to PMA, blocked induction of Fas-resistance by anti-Ig but had no effect on IL-4Rinduced Fas-resistance[35]. Conversely, the loss of STAT6 (in B cells obtained from STAT6-deficient mice) blocked induction of Fas-resistance by IL-4 but had no effect on sIg-induced Fas-resistance[42]. (Of interest, sIg engagement was recently shown to trigger STAT6 activation[43], which raised the possibility that STAT6 might form the basis of a common pathway leading both from sIg and from IL-4R to inducible Fasresistance; however, the results discussed above negate this possibility). Further, the relative speed with which Fas-resistance was established also differed for anti-Ig and IL-4. Whereas anti-Ig acted rapidly to produce Fas-resistance that was apparent at $3 \mathrm{~h}$, and maximal after $12 \mathrm{~h}$, IL-4-induced Fas-resistance developed much more slowly and only reached a maximum after $24 \mathrm{~h}$ of exposure[35],[37]. These results taken together indicate that sIg and IL-4 receptors utilize at least partially non-overlapping intracellular signaling pathways to bring about Fas-resistance.

The timecourse experiments were carried out by stimulating B cells with CD40L for a total of $48 \mathrm{~h}$, and adding anti-Ig or IL-4 at various times before the end of the culture period. Because B cell treatment with CD40L for $24 \mathrm{~h}$ was sufficient to induce Fassensitivity, the capacity of anti-Ig and IL-4 to produce maximal Fas-resistance when added $24 \mathrm{~h}$ before the end of $48 \mathrm{~h}$ culture periods with CD40L means that these reagents do not simply prevent the development of Fas-sensitivity in response to CD40 engagement but actually reverse susceptibility to Fas-mediated apoptosis that has already been established.

Additional work on metabolic pathways has focused on sIg-induced Fas-resistance. In view of the PKC requirement for Fas-resistance produced by anti-Ig, the capacity of PKC-activating phorbol ester treatment to induce Fas-resistance was examined. Phorbol ester produced only partial protection against Fas-mediated apoptosis, whereas the combination of a phorbol ester plus a calcium ionophore brought about virtually complete Fas-resistance, the level of which was as high or higher than that associated with anti-Ig[35]. This recapitulates results with cell cycle progression as an endpoint, for which only the combination of a phorbol ester and a calcium ionophore, which together mimic the effects of sIg-triggered PLC-mediated second messengers, produces S phase entry[44],[45]. Thus, Fas-resistance can be established in the absence of specific receptor engagement by appropriate stimulation of intracellular mediators.

Btk is an indispensable intermediary in the sIg pathway leading to cell cycle progression, as evidenced by the complete failure of S phase entry in B cells from xid mice, in which Btk is mutated, or in B cells from Btk knock-out mice, in which Btk is absent 
Inducible Fas-resistance in B cells

[46-48]. In view of the importance of Btk for sIg-induced proliferation, the role of Btk in sIg signaling for Fas-resistance was examined using B cells from both kinds of mice. With xid B cells, the levels of Fas-sensitivity produced by CD40L stimulation, and of Fas-resistance induced by anti-Ig, were indistinguishable from results obtained with wild-type control B cells. With Btk knock-out B cells, CD40L stimulation produced Fas-sensitivity that was minimally increased (by 20-30 \%) over that observed with control B cells; however, there was no difference between B cells obtained from Btk knock-out and from wild-type control mice in the degree of Fas-resistance produced by anti-Ig[49]. The unexpected minor increase in Fas-sensitivity in Btk knock-out B cells may relate to the report that Btk binds Fas and interferes with Fas signaling for cell death, although the modulation of Fas-sensitivity observed here in murine B cells was much less impressive than that reported for chicken DT40 B cells[50]. The xid and Btk knock-out results together indicate that Btk plays no role in sIg signaling for Fasresistance. Thus, the signaling pathway that leads from sIg to Fas-resistance differs completely from the route leading from sIg to S phase entry, in that Btk is absolutely required for the latter but not at all for the former.

The finding that Fas-resistance develops over a period of hours following anti-Ig treatment suggested that new gene expression might play a key role. To examine this possibility, B cells were treated with inhibitors of macromolecular synthesis along with anti-Ig during the last $6 \mathrm{~h}$ of $48 \mathrm{~h}$ cultures with CD40L (longer periods of exposure being precluded by drug toxicity); the addition of either cycloheximide or actinomycin D completely blocked the induction of Fas-resistance by anti-Ig[35],[51]. Thus, Fasresistance induced by sIg engagement appears to depend on new gene expression and new protein synthesis. These results also indicate that the mechanism responsible for sIg-induced Fas-resistance in primary B cells differs from that reported for the A20 B cell line, which is not interrupted by cycloheximide[52].

The dependence of sIg-induced Fas-resistance on new gene expression implies, in turn, a role for factors that transcriptionally activate anti-apoptotic genes. A candidate factor might be $\mathrm{NF}-\kappa \mathrm{B}$, a transactivating complex that is developmentally regulated and is induced as a result of sIg engagement, inasmuch as NF- $\kappa \mathrm{B}$ has been reported to regulate the expression of some anti-apoptotic genes, and to influence the Fas-sensitivity of $\mathrm{T}$ cell lines[53-61]. To evaluate the role of NF- $\kappa \mathrm{B}$, inhibitors of nuclear NF- $\kappa \mathrm{B}$ translocation were added along with anti-Ig during the last $12 \mathrm{~h}$ of $48 \mathrm{~h}$ cultures with CD40L; the proteasome inhibitor lactacystin[62],[63] and the antioxidant pyrrolidinedithiocarbamate (PDTC) [64] each completely blocked sIg-induced Fasresistance, while having no effect on the ability of CD40L alone to upregulate Fas expression and to produce Fas-sensitivity. As an important corollary, lactacystin and PDTC also inhibited the activation of NF- $\kappa \mathrm{B}$ that was produced when anti-Ig was added to CD40L-stimulated B cells. These results with two different inhibitors, operating through two different mechanisms of action, indicate that sIg signaling for Fas-resistance requires NF- $\kappa \mathrm{B}$ activation and is thus NF- $\kappa \mathrm{B}$-dependent. Notably, PMA induces 
vigorous nuclear translocation of $\mathrm{NF}-\kappa \mathrm{B}$ in mature $\mathrm{B}$ cells but only partial resistance to Fas-mediated apoptosis[35],[53], suggesting that either NF- $\kappa \mathrm{B}$ induction is a necessary but not sufficient condition for Fas-resistance, or that Fas-resistance depends on the induction of sIg-specific $\kappa \mathrm{B}$-binding complexes.

Recently, two groups reported that sIg-induced NF- $\kappa \mathrm{B}$ activation, like sIg-induced proliferation, is Btk-dependent[65], [66]. In contrast, the experiments discussed above indicate that sIg-induced Fas-resistance requires $\mathrm{NF}-\kappa \mathrm{B}$ yet takes place in the absence of Btk. The reason for these seemingly conflicting results remains unclear. It may be that prior CD40L stimulation establishes a new intracellular signaling pathway through which sIg activates NF- $\kappa \mathrm{B}$ in the absence of Btk. Or it may be that induction of Fasresistance requires only a very minimal threshold level of NF- $\kappa \mathrm{B}$. Alternatively, inhibitors of NF- $\kappa \mathrm{B}$ activation may at the same time inhibit another signaling mediator, and this latter mediator, not $\mathrm{NF}-\kappa \mathrm{B}$, is the important molecular effector. These possibilities are currently being tested.

\section{Two terminal effectors of Fas-resistance: Bcl- $\mathrm{x}_{\mathrm{L}}$ and FLIP}

The identity of gene products whose synthesis might be responsible for inducible Fasresistance was sought by testing likely prospects according to two criteria: upregulation of expression under conditions that produce Fas-resistance, and, induction of Fas-resistance by upregulated expression in the absence of receptor engagement. Initial experiments designed to detect such molecules focused on members of the Bcl-2 family, some members of which interfere with mitochondrial cytochrome c release[67]. A number of Bcl-2- homologous genes were assayed for induction by anti-Ig treatment of CD40Lstimulated B cells through RT-PCR. Only bcl- $\mathrm{x}_{\mathrm{L}}$ was upregulated. Bcl- $\mathrm{x}_{\mathrm{L}}$ expression was strongly induced at the RNA level within an hour of anti-Ig addition, and at the protein level within 6-12 $\mathrm{h}$ [68]. B cells obtained from Bcl- $\mathrm{x}_{\mathrm{L}}$-overexpressing transgenic mice were then tested for susceptibility to Th1 cell mediated cytotoxicity after stimulation by CD40L alone, in order to determine the capacity of $\mathrm{Bcl}-\mathrm{x}_{\mathrm{L}}$, overexpressed in isolation, to produce Fas-resistance. These B cells were (3-fold) less sensitive to Fas killing than wild-type littermate control B cells, despite similar levels of upregulated Fas expression, and similar levels of activation as judged by thymidine incorporation[68]. Thus, Bcl- $\mathrm{x}_{\mathrm{L}}$ appears to account for at least a portion of sIg-induced Fas-resistance because, expression was upregulated coordinately with induction of Fas-resistance (in both murine and human B cells, reference[69]), and, because isolated overexpression diminished B cell susceptibility to Fas killing separate and apart from any other potential effects of sIg engagement (although in connection with this last point it should be mentioned that the capacity of Bcl- $\mathrm{x}_{\mathrm{L}}$ to inhibit Fas-mediated apoptosis in B cell lines has been questioned, reference[70]). Further, the reduction in susceptibility to Th1-induced cytotoxicity produced by Bcl- $\mathrm{x}_{\mathrm{L}}$ suggests that Fas death signaling in B cells involves mitochondrial cytochrome $\mathrm{c}$ release; this notion is supported by our observation that inducibly Fas-resistant B cells are protected against apoptosis produced by C2-ceramide, 
Inducible Fas-resistance in B cells

the cytotoxicity of which has been associated with mitochondrial damage[71-75][71-75].

There are, however, several indications that Bcl- $\mathrm{x}_{\mathrm{L}}$ does not fully account for Fasresistance produced by anti-Ig: 1) the loss of Fas-sensitivity in (CD40L-stimulated) Bcl$\mathrm{x}_{\mathrm{L}}$-overexpressing $\mathrm{B}$ cells was incomplete, and was less dramatic than the loss of Fassensitivity observed in wild-type B cells stimulated by anti-Ig plus CD40L; 2) anti-Ig treatment of (CD40L-stimulated) Bcl- $\mathrm{x}_{\mathrm{L}}$-overexpressing B cells produced a further (approximately 3-fold) reduction in the already muted Fas-sensitivity of these B cells; and, 3) Bcl- $\mathrm{x}_{\mathrm{L}}$ \} protein did not appear in normal CD40L-stimulated B cells treated with anti-Ig until after the initial onset of diminished sensitivity to Fas. These considerations strongly suggest that at least one other anti-Ig-responsive molecule plays a role in blocking Fas killing following sIg engagement.

Additional experiments designed to elucidate the identity of gene products potentially responsible for sIg-induced Fas-resistance focused on evaluation of FLIP. FLIP is a FLICE/caspase 8 homolog that lacks an active enzyme site and thus competitively inhibits downstream signaling that normally occurs following FLICE/caspase 8 binding to FADD[76-79]. Our early Northern blot experiments suggested that some FLIP expression was induced by anti-Ig treatment of CD40L-stimulated B cells, but the data were inconclusive owing to the very low level of FLIP expression detected. However, definitive results were subsequently obtained by RT-PCR, which showed that FLIP RNA expression was induced within an hour of adding anti-Ig to CD40L-stimulated B cells, and that FLIP protein expression was upregulated within $6 \mathrm{~h}$. These results were recently extended by reports indicating that FLIP overexpression interferes with Fasmediated apoptosis in primary B cells and in B cell lines[80],[81]. These studies together strongly suggest that FLIP is involved in bringing about sIg-induced resistance to Fas-mediated apoptosis because the two criteria discussed above were met, as described earlier for Bcl- $\mathrm{x}_{\mathrm{L}}$ : FLIP expression was upregulated coordinately with induction of Fas-resistance by anti-Ig, and isolated FLIP overexpression diminished B cell susceptibility to Fas signaling for cell death. (In these studies a number of other known anti-apoptotic genes screened as outlined above failed to meet the criterion of expression coincident with induction of Fas-resistance, including A1, A20, BAG-1, Bcl-2, IAP1, IAP-2, Ich-1S, IEX-1L and survivin, references[82-90].

\section{Identification of a novel Fas apoptosis inhibitory molecule (FAIM)}

To identify additional genes that might be responsible for resistance to Fas-mediated apoptosis without regard to conserved motifs or known properties, transcripts induced as a result of anti-Ig treatment that produces Fas-resistance were detected using a differential display strategy[91]. Through this approach, a completely novel $1.2 \mathrm{~kb}$ sequence was cloned that contains an open reading frame encoding a protein product of 179 amino acids predicted to reflect a stable, soluble, $\beta$-strand-rich molecule that is slightly acidic[51]. The function of this gene was evaluated with BAL-17 murine B lymphoma cells, the activation responses of which mimic those of primary B cells in a 
number of ways[92], including upregulated Fas expression and increased sensitivity to Fas killing following CD40L stimulation. BAL-17 B cells were transfected with the gene cloned in pBKCMV, or with empty vector, selected in G418, and then stimulated with CD40L for $24 \mathrm{~h}$ and examined for susceptibility to Th1 cell-mediated cytotoxicity. Cytotoxicity was assessed in two ways, by chromium release after exposure of transfectants to FasL-bearing Th1 effector cells, and by propidium iodide-staining for subdiploid DNA after treatment of transfectants with Jo-2 anti-Fas antibody. Regardless of the means by which Fas was engaged or cytotoxicity was assessed, Fas-mediated apoptosis was markedly reduced in B cells expressing the gene of interest as compared to vector transfectants, using both G418-resistant pools and stably transfected lines cloned by limiting dilution[51]. Considering the dose-response curve with Th1 effector cells, Fas-resistance produced by the gene of interest amounted to a greater than 9 -fold level of protection against Fas-mediated apoptosis. These results indicate that the differentially expressed gene encodes a Fas Apoptosis Inhibitory Molecule, which we termed FAIM. The anti-apoptotic function of FAIM was demonstrated further at a biochemical level by evaluating cleavage products of poly-ADP ribose polymerase (PARP) that result from caspase activation[93, 94]. PARP fragments were detected within 40 minutes of treating vector-transfected BAL-17 B cells with Jo-2 anti-Fas antibody, whereas such fragments were not observed in faim-transfected BAL-17 B cells up to 60 minutes after antibody treatment[51]. This correlated well with the transgenically enhanced level of FAIM expression, which was demonstrated by Western blotting to be greatly increased over the endogenous levels present in vector-transfected controls. These results indicate that FAIM blocks Fas killing by interfering with a step prior to terminal caspase activity.

As might be expected from the original selection conditions for differential display analysis, faim mRNA increased within an hour of adding anti-Ig to CD40L-stimulated $\mathrm{B}$ cells, and expression continued to rise over the next $5 \mathrm{~h}$, as shown by Northern blotting. Along the same lines, FAIM protein increased within $6 \mathrm{~h}$ of treating CD40Lstimulated B cells with anti-Ig, and expression continued to rise, peaking at $12 \mathrm{~h}$, as detected by Western blotting[51]. The finding of substantially increased FAIM expression in splenocytes obtained from sheep red blood cell-immune animals, as compared to splenocytes obtained from control animals injected with saline, suggests that these in vitro studies of inducible FAIM expression bear relevance for physiological immune responses. Thus, upregulation of FAIM expression coincides with B cell treatment by Fas-resistance-inducing regimens in vitro, and with induction of foreign antigen-specific immune responses in vivo.

The murine faim sequence contains no known effector domains; that is, it lacks kinase or phosphatase domains, caspase or CARD domains, $\mathrm{PH}$ or SH2 domains, and so forth. However, we readily identified highly homologous faim sequences in other species, indicating strong evolutionary conservation[51]. Human faim was obtained by constructing a consensus sequence from overlapping expressed sequence tag (EST) 
Inducible Fas-resistance in B cells

fragments that share some homology with mouse faim, plus direct sequencing of a single EST clone that completely spans the putative human transcript[95]. The predicted amino acid sequence of human FAIM is $90 \%$ identical to the predicted amino acid sequence of mouse FAIM. These results were extended by Southern analysis showing hybridization by a mouse faim probe to genomic DNA from all mammalian species tested (human, monkey, rat, mouse, dog, cow, and rabbit) (unpublished observations). Worm faim was identified by directly sequencing cDNA amplified by PCR, using primers based on our own manual analysis of the putative exonic structure of a C. elegans genomic sequence of unknown function that contains discrete regions of homology with mouse faim. The predicted amino acid sequence of C. elegans FAIM is 50\% identical to the predicted amino acid sequence of mouse FAIM. Fly faim was obtained by computer-aided searching of the recently posted $\mathrm{D}$. melanogaster genome, using accepted algorithms to define putative exon/intron structure. The putative predicted amino acid sequence of $\mathrm{D}$. melanogaster FAIM is 36\% identical to the predicted amino acid sequence of mouse FAIM, with the caveat that the fly sequence has not been amplified directly from cDNA [96]. Examination of the predicted FAIM sequences from these 4 species indicates that specific regions of very high identity exist within the amino terminal region that likely represent novel anti-apoptotic effector domains or domains required for FAIM association with another mediator or modulator protein. Two distinct short stretches of 12 and 13 amino acids each are 69-75\% identical across all four species[96]. The evolutionary conservation of faim strongly suggests that the faim gene product is an important regulatory molecule that has been favored for retention throughout phylogeny, and thus likely plays a key role in cellular viability or other processes. (Since there is no known Fas homolog in C. elegans or D. melanogaster, it is presumed that FAIM carries out a similar, but possibly not Fas-specific, anti-apoptotic function in the worm and the fly.)

Two other characteristics of FAIM suggest that it plays an important role in regulating cellular processes. 1) The faim gene is broadly expressed. High level faim gene expression was documented in murine brain, thymus, kidney and spleen by Northern blotting, and in additional normal tissues by RT-PCR[51],[96], suggesting that FAIM performs an essential function in non-lymphoid, as well as in lymphoid, cells. 2) The faim gene localizes to a cytogenetic region associated with disease. Human faim was localized to chromosome 3q22-25 by fluorescence in situ hybridization (FISH), and to chromosome 3q25 by radiation hybrid analysis of a faim-containing EST[96]. This region contains loci associated with B cell lymphoma, acute non-lymphocytic leukemia, and squamous cell carcinoma of the lung[97-99]. The mechanism by which mutation of a gene that blocks Th1 cell-mediated cytotoxicity might inure to the benefit of malignant cells is speculative at best, but such changes might increase the level of FAIM expression or enhance the anti-apoptotic activity of FAIM. Recently, inhibition of Fasmediated apoptosis by overexpression of FLIP was shown to increase lymphoma tumorigenicity[100],[101], supporting the concept that modulation of Fas signaling for cell 
death plays a role in determining the effectiveness of anti-tumor immunity, and providing a rationale for a connection between tumor-associated loci and anti-apoptotic genes like faim.

During our initial cloning efforts the faim sequence was obtained from two sourcesa mouse thymus library and, subsequently, a mouse brain library. However, the two sequences differ. The original thymus-derived FAIM sequence, now termed FAIM-Short (FAIM-S), is shorter by 22 ' amino acids in comparison to the brain-derived sequence, now termed FAIM-Long (FAIM- L)[96]. Recently we identified a human faim-L homolog among publicly available EST fragments, which similarly encodes 22 additional 5' amino acids, 21 of which are identical to the additional sequence in murine FAIM$\mathrm{L}$, indicating a high degree of homology in this region, although this sequence contains no presently recognized effector motifs. To clarify the origin of the two faim sequences, the mouse faim genomic locus was characterized[96]. Mouse faim was localized to a region (9f1) syntenic to the chromosomal location of human faim by FISH analysis. Three BAC clones containing the faim locus were obtained by screening a murine $129 \mathrm{~Sv}$ genomic library, and one of these clones was used as a template for analysis. All intron/ exon boundaries were confirmed by direct sequencing[102]. The murine faim locus was shown to consist of 6 exons. Exons IV and VI in M. musculus were each found to represent the fusion of 2 exons identified in C. elegans, so that the intron/exon organization is simplified in the higher organism, which although unusual is not unprecedented[103-107]. Two putative translation initiation sites were identified on separate exons (II and III), indicating that faim-L and faim-S result from alternative splicing. Through PCR amplification utilizing a 5' primer that corresponds to the 5' untranslated region, faim-L was shown to be expressed in primary tissue, although among multiple tissues examined, expression of faim-L was extremely tissue-specific, and was strictly limited to the brain[96]. The function of FAIM-L is presently unknown, and the possibility that FAIM-L is active only in the brain, or that FAIM-L fulfills a unique role in the brain, has not been ruled out.

These results indicate that faim is a novel gene without precedent in publicly available databases, whose protein product inhibits Fas-mediated apoptosis, and whose expression is upregulated coordinately with induction of Fas-resistance by sIg engagement in vitro and during antigen-specific immune responses in vivo. These features suggest that FAIM is involved in the physiological regulation of immune cell activity, inducibly suppressing Fas signaling for cell death along with Bcl- $x_{L}$ and FLIP. The multigenic nature of sIg-induced Fas-resistance suggests, in a larger sense, that the relative susceptibility of $\mathrm{B}$ cells to Fas-mediated apoptosis is determined by the balance between multiple pro- and anti-apoptotic molecules, whose expression changes rapidly in response to shifting environmental conditions, such as the presence of antigen and/ or T cell-derived lymphokine. 
Inducible Fas-resistance in B cells

\section{Speculative role for Fas-resistance}

$\mathrm{T}$ cell activation results in upregulation of CD40L expression[108-110], as well as upregulation of FasL expression[8],[1111-114]. As much as engagement of (constitutively expressed) B cell CD40 is necessary for T-dependent stimulation, CD40 triggering also upregulates Fas expression, and engagement of B cell Fas by T cell FasL initiates apoptotic events. In view of this, activated $\mathrm{T}$ cells represent a potential threat to $\mathrm{B}$ cell viability, and this may well be the point at which inducible Fas-resistance plays a key role, by protecting B cells against FasL expressed by interacting Th1 cells and thereby promoting B cell immune responses. Two manifestations of this have been documented. 1) Fas-resistant $B$ cells present antigen more effectively than Fas-sensitive B cells. This was demonstrated by experiments in which antigen-pulsed, mitomycin-treated Fas-resistant B cells produced greater proliferation of antigen-specific Th1 cells than did similarly treated, Fas-sensitive B cells[115]; improved antigen presentation presumably occurred because Fas-resistant B cells were protected against the threat of death posed by initially activated $\mathrm{T}$ cells, and thus remained viable to present antigen to another round of T cells. 2) Fas-resistant B cells block activation-induced cell death (AICD) of T cells, whereas Fas-sensitive B cells do not. This was demonstrated by experiments in which primed T cells were exposed a second time to antigen (SEB or HEL) presented by $\mathrm{B}$ cells; the resulting Fas-induced cytotoxicity (AICD) of $\mathrm{T}$ cells was markedly reduced when antigen was presented by Fas-resistant B cells, presumably because Fas-bearing, apoptosis-resistant B cells competitively inhibited T cell FasL, preventing interaction with T cell Fas[116]. These results suggest that Fas-resistance induced in B cells may enhance and perpetuate $\mathrm{T}$, as well as $\mathrm{B}$, cell responses. The idea that inducible Fasresistance modulates $\mathrm{B}$ and $\mathrm{T}$ cell deletion, and promotes $\mathrm{B}$ and $\mathrm{T}$ cell responses, is further supported, somewhat indirectly, by the observed durability of the receptorspecific phenotype, which was unchanged when B cells were washed and re-cultured for $24 \mathrm{~h}$ in medium prior to assay of Th1 cell-mediated cytotoxicity.

\section{Fas-resistance in tolerant $B$ cells}

The model described above, which suggests that inducible Fas-resistance acts to protect B cells from FasL-bearing, activated T cells, raises the issue of autoreactive B cells, the very B cells that are dysregulated in the absence of Fas expression. Inasmuch as these B cells appear to be eliminated in a Fas-dependent fashion[15],[117-121], the induction of Fas-resistance (as a result of interaction with ever present self antigen) could lead to deleterious consequences, because of the possibility that normal processes of autoreactive B cell deletion might be thwarted. It would seem necessary for the rules governing the regulation of Fas-mediated apoptosis to be different for autoreactive B cells in comparison to normal (foreign antigen-specific) B cells.

To address this issue, B cells were obtained from transgenic mice expressing antiHEL antigen receptors, and from double transgenic mice that express both the antiHEL receptor as well as a transgene encoding soluble HEL (anti-HEL/sHEL). B cells 
from anti-HEL/sHEL mice are continually exposed to what is, for them, autoantigen, as a result of which these transgenically autoreactive $B$ cells are tolerant, and thus do not signal normally through sIg[122-124]. B cells from both kinds of transgenic mice were stimulated with CD40L alone or with CD40L in combination with soluble HEL, and tested for susceptibility to Fas-mediated apoptosis. The addition of soluble HEL produced resistance to Fas killing only in B cells from anti-HEL mice; there was no effect of sHEL on the Fas-sensitivity of CD40L-stimulated B cells from anti-HEL/sHEL mice, despite the fact that upregulated levels of Fas expression and Fas-sensitivity produced by CD40L were similar for B cells obtained from single transgenic and double transgenic mice[36]. Thus, specific antigen differentially induced Fas-resistance in non-autoreactive and in autoreactive B cells, succeeding in the former but failing in the latter. However, it was noted that anti-Ig produced similar levels of Fas-resistance in CD40L-stimulated B cells from single and double transgenic mice, suggesting that autoreactive B cells are not totally intractable to induction of Fas-resistance through sIg signaling but, instead, may simply require a higher degree of sIg crosslinking for this outcome. To examine this issue, B cells from anti-HEL/sHEL mice were stimulated with CD40L alone or with CD40L in combination with biotinylated SHEL, with or without additional crosslinking imposed by streptavidin. In the presence of streptavidin, autoreactive B cells from anti-HEL/sHEL mice acquired resistance to Fas-mediated apoptosis, similar in magnitude to that produced by anti-Ig[36]. These results strongly suggest that in autoreactive B cells an elevated threshold of sIg signaling must be exceeded for induction of Fas-resistance, as compared to the degree of sIg signaling needed for induction of Fas-resistance in foreign-antigen-specific B cells. In this way the possibility that self antigen might induce Fas-resistance through sIg signaling in autoreactive B cells is minimized, and sIg-induced Fas-resistance is unlikely to contribute to serological autoimmunity under normal circumstances.

The situation with IL-4 is very different. Similar levels of Fas-resistance were produced by IL-4 in CD40L-stimulated B cells obtained from single and double transgenic mice[36]. Thus, the capacity of IL-4R engagement to produce Fas-resistance was not altered in autoreactive B cells. These results suggest the possibility that autoreactive B cells might escape Fas-dependent deletion because of IL-4R signaling (which, under normal circumstances, would be averted by mechanisms that maintain $\mathrm{T}$ cell tolerance). In support of this notion, serum samples ( 5 out of 5 tested) obtained from IL-4overexpressing transgenic mice[125] were found to contain autoantibodies by indirect immunofluorescence on HEp-2 cells[37]. HEp-2-staining serum autoantibodies were similarly reported in sera obtained from a separate IL-4 transgenic line[126]. More recently, the role of IL-4 has been examined using the defined anti-HEL/sHEL system by breeding triple transgenic (anti-HEL/sHEL/IL-4) animals and then testing sera for anti-HEL antibody. Preliminary results indicate that these mice (10 out of 10 examined) produced increasing amounts of serum anti-HEL autoantibody with increasing age, and in so doing broke tolerance. Although none of these studies precludes the possibil- 
Inducible Fas-resistance in B cells

ity that IL-4 affects a non-B cell target, all are consistent with the ability of IL-4 to induce Fas-resistance and thereby interfere with the known Fas-deletional pathway for elimination of autoreactive B cells. This conclusion is supported by the observation that constitutive expression of B7.2 led to a breakdown in tolerance in anti-HEL/sHEL transgenic mice[127], which our results infer was due to complete stimulation of $\mathrm{T}$ cells to produce IL-4 which in turn induced B cell Fas-resistance.

The results discussed above suggest that induction of Fas-resistance, dysregulation of autoreactive B cells and disruption of B cell tolerance, along with the appearance of autoantibodies, could result either from sIg stimulation that exceeds a certain threshold, as might be produced by immune complexes, or from IL-4R engagement not directly related to cognate interactions, as might occur during periods of heightened immunological stress that may be accompanied by lymphokine overproduction[128].

\section{SUMMARY AND DISCUSSION}

The most important conclusion to be drawn from these studies is that B cells are not monomorphic targets for Th1 cell-mediated cytotoxicity but rather modulate their own intrinsic susceptibility to Fas-mediated apoptosis in response to specific environmental cues in a dynamic fashion in which Fas- sensitivity changes rapidly as a result of specific receptor binding. Engagement of the B cell antigen receptor or the IL-4 receptor triggers at least partially non-overlapping, inducible pathways that result in a durable state of Fas-resistance that is mediated by Bcl-xL, FLIP, and FAIM, and possibly other molecules that are as yet unknown. Fas-resistance likely plays an important role during critical, early B cell:T cell interactions, protecting B cells from the inherent threat to survival posed by FasL expression on the part of activated T cells. In this way inducible Fas-resistance is hypothesized to enhance serological immune responses and, perhaps, to promote $\mathrm{T}$ cell responses by improving antigen presentation and by blocking AICD. Notably, Fas-resistance, as represented by the absence of functional Fas expression in mutant mice or by overexpression of FLIP in retrovirally transduced chimeras, produces serological autoreactivity, and thus may constitute an etiologic factor in clinically important autoimmunity[26], [28],[80]. In other words, the presence or absence of receptor-induced Fas-resistance is likely to be a key element in determining the usefulness or aberrance of real world immune responses.

Modulation of Fas-sensitivity is not limited to B cells. T cells may upregulate Fas expression but still fail to undergo apoptosis in response to Fas signaling. This occurs shortly after activation through the $\mathrm{T}$ cell receptor in vitro. With time and continued stimulation, the Fas-resistant phenotype reverses, and $\mathrm{T}$ cells become Fas-sensitive, without any change in the elevated level of Fas expression, perhaps as a result of IL-2R signaling and alterations in the levels of Bcl-xL and FLIP, although the precise mechanism remains uncertain[76],[129-133]. Additional reports suggest that Fas-sensitivity is modulated in anergic $\mathrm{T}$ cells, memory $\mathrm{T}$ cells, primed $\mathrm{T}$ cells and Th2 cells[134-139]. 
Thus, inducible changes in the sensitivity of $\mathrm{T}$ cells to Fas-mediated apoptosis likely play a role in $\mathrm{T}$ cell homeostasis and in $\mathrm{T}$ cell immune responses.

Malignant cells, both lymphoid and non-lymphoid, manifest resistance to Fasmediated apoptosis[140-149]. Inasmuch as inhibition of Fas signaling for cell death is associated with tumor development and progression, it appears that Fas-mediated apoptosis constitutes at least a portion of anti-tumor immunity, and that some malignancies take advantage of mechanisms that block Fas killing to maintain viability and co-exist within the framework of a normal immune system[100,101], [150-153]. The mechanisms utilized by malignant cells may represent perversions of the physiological means by which B cells normally inhibit susceptibility to Fas-mediated apoptosis in a receptor-specific fashion. If true, molecules involved in establishing sIg-induced Fasresistance might form targets for pharmacologic manipulation of the apoptotic balance between host and tumor, including NF- $\kappa$ B, Bcl- $\mathrm{x}_{\mathrm{L}}$, FLIP, and/or FAIM[51,56, 68, 76,154, 155].

The sum of the work described above, in conjunction with evidence provided by other investigators, strongly suggests that the regulation and dysregulation of Fas-mediated apoptosis contributes to the level and importance of normal immune, autoimmune, and tumor-immune responses. New insights are likely to arise from further study of the inter-relationships between surface receptor engagement and susceptibility to Fas signaling, and of mechanisms and molecules responsible for inducible Fas-resistance, which may provide new targets for influencing normal and abnormal immune activity.

\section{ACKNOWLEDGEMENTS}

This work was supported by United States Public Health Service grants AI40181 and AI45112 awarded by the National Institutes of Health and by a grant from the Arthritis Foundation.

\section{REFERENCES}

[1] Yonehara S, Ishii A, Yonehara M. A cell-killing monoclonal antibody (anti-Fas) to a cell surface antigen co-downregulated with the receptor of tumor necrosis factor. J Exp Med 1989; 169:1747-56.

[2] Trauth BC, Klas C, Peters AM, et al. Monoclonal antibody- mediated tumor regression by induction of apoptosis. Science 1989; 245:301-5.

[3] Nagata S. Apoptosis by death factor. Cell 1997; 88:355-65.

[4] Chinnaiyan AM, O'Rourke K, Yu GL, et al. Signal transduction by DR3, a death domain-containing receptor related to TNFR-1 and CD95. Science 1996; ,B. 274:990-2.

[5] Chaudhary PM, Eby M, Jasmin A, Bookwalter A, Murray J, Hood L. Death receptor 5, a new member of the TNFR family, and DR4 induce FADD- dependent apoptosis and activate the NF- $\kappa$ B pathway. Immunity 1997; 7:821-30.

[6] Schneider P, Thome M, Burns K, et al. TRAIL receptors 1 (DR4) and 2 (DR5) signal FADD-dependent apoptosis and activate NF- $к$ B. Immunity 1997; 7:831-6.

[7] Yeh WC, Pompa JL, McCurrach ME, et al. FADD: essential for embryo development and signaling from some, but not all, inducers of apoptosis. Science 1998; 279:1954-8. 
Inducible Fas-resistance in B cells

[8] Suda T, Okazaki T, Naito Y, et al. Expression of the Fas ligand in cells of T cell lineage. J Immunol 1995; 154:3806-13.

[9] Smyth MJ, Sutton VR, Kershaw MH, Trapani JA. Xenospecific cytotoxic T lymphocytes use perforinand Fas-mediated lytic pathways. Transplantation 1996; 62:1529-32.

[10] Hahn S, Gehri R, Erb P. Mechanism and biological significance of CD4-mediated cytotoxicity. Immunol Rev 1995; 146:57-79.

[11] Arase H, Arase N, Saito T. Fas-mediated cytotoxicity by freshly isolated natural killer cells. J Exp Med 1995; 181:1235-8.

[12] Montel AH, Bochan MR, Hobbs JA, Lynch DH, Brahmi Z. Fas involvement in cytotoxicity mediated by human NK cells. Cell Immunol 1995; 166:236-46.

[13] Oshimi Y, Oda S, Honda Y, Nagata S, Miyazaki S. Involvement of Fas ligand and Fas-mediated pathway in the cytotoxicity of human natural killer cells. J Immunol 1996; 157:2909-15.

[14]Cohen PL, Eisenberg RA. Lpr and gld: single gene models of systemic autoimmunity and lymphoproliferative disease. Annu Rev Immunol 1991; 9:243-69.

[15] Watanabe-Fukunaga R, Brannan CI, Copeland NG, Jenkins NA, Nagata S. Lymphoproliferation disorder in mice explained by defects in Fas antigen that mediates apoptosis. Nature 1992; 356:3147.

[16] Takahashi T, Tanaka M, Brannan CI, et al. Generalized lymphoproliferative disease in mice, caused by a point mutation in the Fas ligand. Cell 1994; 76:969-76.

[17] Fisher GH, Rosenberg FJ, Straus SE, et al. Dominant interfering Fas gene mutations impair apoptosis in a human autoimmune lymphoproliferative syndrome. Cell 1995; 81:935-46.

[18] Rieux-Laucat F, Le Deist F, Hivroz C, et al. Mutations in Fas associated with human lymphoproliferative syndrome and autoimmunity. Science 1995; 268:1347-9.

[19] Drappa J, Vaishnaw AK, Sullivan KE, Chu JL, Elkon KB. Fas gene mutations in the Canale-Smith syndrome, an inherited lymphoproliferative disorder associated with autoimmunity [see comments]. N Engl J Med 1996; 335:1643-9.

[20] Wu J, Wilson J, He J, Xiang L, Schur PH, Mountz JD. Fas ligand mutation in a patient with systemic lupus erythematosus and lymphoproliferative disease. J Clin Invest 1996; 98:1107-13.

[21] Le Deist F, Emile JF, Rieux- Laucat F, et al. Clinical, immunological, and pathological consequences of Fas-deficient conditions. Lancet 1996; 348:719-23.

[22] Wang J, Zheng L, Lobito A, et al. Inherited human Caspase 10 mutations underlie defective lymphocyte and dendritic cell apoptosis in autoimmune lymphoproliferative syndrome type II. Cell 1999; 98:47-58.

[23] Nagata S, Suda T. Fas and Fas ligand: lpr and gld mutations. Immunol Today 1995; 16:39-43.

[24] Adachi M, SuematsuS, Suda T, et al. Enhanced and accelerated lymphoproliferation in Fas-null mice. Proc Natl Acad Sci U S A 1996; 93:2131-6.

[25] Perkins DL, Michaelson J, Glaser RM, Marshak-Rothstein A. Selective elimination of non- lpr lymphoid cells in mice undergoing lpr-mediated graft-vs-host disease. J Immunol 1987; 139:1406-13.

[26] Nemazee D, Guiet C, Buerki K, Marshak-Rothstein A. B lymphocytes from the autoimmune-prone mouse strain MLR/ lpr manifest an intrinsic defect in tetraparental MRL/ lpr in equilibrium DBA/2 chimeras. J Immunol 1991; 147:2536-9.

[27] Sobel ES, Kakkaaiah VN, Schiffenbauer J, Reap EA, Cohen PL, Eisenberg RA. Novel immunoregulatory B cell pathways revealed by lpr-+ mixed chimeras. J Immunol 1998; 160:1497-503.

[28] Fukuyama H, Adachi M, Suematsu S, et al. Transgenic expression of Fas in T cells blocks lymphoproliferation but not autoimmune disease in MRL- lpr mice. J Immunol 1998; 160:3805-11.

[29] Stalder T, Hahn S, Erb P. Fas antigen is the major target molecule for CD4+ T cell-mediated cytotoxicity. J Immunol 1994; 152:1127-33.

[30] Ju ST, Cui H, Panka DJ, Ettinger R, Marshak-Rothstein A. Participation of target Fas protein in apoptosis pathway induced by CD4+ Th1 and CD8+ cytotoxic T cells. Proc Natl Acad Sci USA 1994; 91:4185-9. 
[31]Daniel PT, Krammer PH. Activation induces sensitivity toward APO-1 (CD95)-mediated apoptosis in human B cells. J Immunol 1994; 152:5624-32.

[32] Watanabe D, Suda T, Nagata S. Expression of Fas in B cells of the mouse germinal center and Fasdependent killing of activated B cells. Int Immunol 1995; 7:1949-56.

[33]Onel KB, Tucek-Szabo CL, Ashany D, Lacy E, Nikolic-Zugic J, Elkon KB. Expression and function of the murine CD95/FasR/APO-1 receptor in relation to B cell ontogeny. Eur J Immunol 1995; 25:29407.

[34]Rothstein TL, Wang JK, Panka DJ, et al. Protection against Fas-dependent Th1-mediated apoptosis by antigen receptor engagement in B cells. Nature 1995; 374:163-5.

[35]Foote LC, Schneider TJ, Fischer GM, et al. Intracellular signaling for inducible antigen receptormediated Fas resistance in B cells. J Immunol 1996; 157:1878-85.

[36]Foote LC, Marshak-Rothstein A, Rothstein TL. Tolerant B lymphocytes acquire resistance to Fasmediated apoptosis after treatment with interleukin 4 but not after treatment with specific antigen unless a surface immunoglobulin threshold is exceeded. J Exp Med 1998; 187:847-53.

[37] Foote LC, Howard RG, Marshak-Rothstein A, Rothstein TL. IL-4 induces Fas resistance in B cells. J Immunol 1996; 157:2749-53.

[38]Schattner EJ, Elkon KB, Yoo DH, et al. CD40 ligation induces Apo- 1/Fas expression on human B lymphocytes and facilitates apoptosis through the Apo-1/Fas pathway. J Exp Med 1995; 182:1557-65.

[39]Garrone P, Neidhardt EM, Garcia E, Galibert L, van Kooten C, Banchereau J. Fas ligation induces apoptosis of CD40-activated human B lymphocytes. J Exp Med 1995; 182:1265-73.

[40]Lagresle C, Mondiere P, Bella C, Krammer PH, Defrance T. Concurrent engagement of CD40 and the antigen receptor protects naive and memory human B cells from APO-1/Fas-mediated apoptosis. J Exp Med 1996; 183:1377-88.

[41]Rathmell JC, Townsend SE, Xu JC, Flavell RA, Goodnow CC. Expansion or elimination of B cells in vivo: dual roles for CD40- and Fas (CD95)-ligands modulated by the B cell antigen receptor. Cell 1996; 87:319-29.

[42]Wurster AL, Rothstein TL, Grusby MJ. IL-4 protects primary B cells from apoptosis through Stat6dependent upregulation of Bcl-xL. Submitted.

[43]Karras JG, Wang Z, Coniglio SJ, Frank DA, Rothstein TL. Antigen-receptor engagement in B cells induces nuclear expression of STAT5 and STAT6 proteins that bind and transactivate an IFN- $\gamma$ activation site. J Immunol 1996; 157:39-47.

[44]Klaus GG, O'Garra A, Bijsterbosch MK, Holman M. Activation and proliferation signals in mouse B cells. VIII. Induction of DNA synthesis in B cells by a combination of calcium ionophores and phorbol myristate acetate. Eur J Immunol 1986; 16:92-7.

[45]Rothstein TL, Baeker TR, Miller RA, Kolber DL. Stimulation of murine B cells by the combination of calcium ionophore plus phorbol ester. Cell Immunol 1986; 102:364-73.

[46]Sieckmann DG, Asofsky R, Mosier DE, Zitron IM, Paul. Activation of mouse lymphocytes by antiimmunoglobulin. I. Parameters of the proliferative response. J Exp Med 1978; 147:814-29.

[47]Rawlings DJ, Saffran DC, Tsukada S, et al. Mutation of unique region of Bruton' s tyrosine kinase in immunodeficient XID mice. Science 1993; 261:358-61.

[48]Khan WN, Alt FW, Gerstein RM, et al. Defective B cell development and function in Btk-deficient mice. Immunity 1995; 3:283-99.

[49]Negm RS, Schneider TJ, Colarusso TP, Woodland RT, Rothstein TL. Btk does not regulate susceptibility to Fas-mediated apoptosis nor inducible Fas-resistance in murine B cells. In preparation 2000; .

[50]Vassilev A, Ozer Z, Navara C, Mahajan S, Uckun FM. Bruton' s tyrosine kinase as an inhibitor of the Fas/CD95 death-inducing signaling complex. J Biol Chem 1999; 274:1646-56.

[51]Schneider TJ, Fischer GM, Donohoe TJ, Colarusso TP, Rothstein TL. A novel gene coding for a Fas apoptosis inhibitory molecule (FAIM) isolated from inducibly Fas-resistant B lymphocytes. J Exp Med 1999; 189:949-56. 
Inducible Fas-resistance in B cells

[52]Catlett IM, Bishop GA. Cutting edge: a novel mechanism for rescue of B cells from CD95/Fas-mediated apoptosis. J Immunol 1999; 163:2378-81.

[53]Liu JL, Chiles TC, Sen RJ, Rothstein TL. Inducible nuclear expression of NF- $\kappa$ B in primary B cells stimulated through the surface Ig receptor. J Immunol 1991; 146:1685-91.

[54]Rooney JW, Dubois PM, Sibley CH. Cross-linking of surface IgM activates NF- $\kappa$ B in B lymphocyte. Eur J Immunol 1991; 21:2993-8.

[55]Ghosh S. Regulation of inducible gene expression by the transcription factor NF- $\kappa \mathrm{B}$. Immunol Res 1999; 19:183-9.

[56]Jeremias I, Kupatt C, Baumann B, Herr I, Wirth T, Debatin KM. Inhibition of nuclear factor $k$ B activation attenuates apoptosis resistance in lymphoid cells. Blood 1998; 91:4624-31.

[57]Dudley E, Hornung F, Zheng L, Scherer D, Ballard D, Lenardo M. NF- $\kappa$ B regulates Fas/APO-1/CD95and TCR-mediated apoptosis of T lymphocytes. Eur J Immunol 1999; 29:878-86.

[58]Zong WX, Edelstein LC, Chen C, Bash J, Gelinas C. The prosurvival Bcl-2 homolog Bfl-1/A1 is a direct transcriptional target of NF- $\kappa$ B that blocks TNF $a$-induced apoptosis. Genes Dev 1999; 13: 382-7.

[59]Grumont RJ, Rourke IJ, Gerondakis S. Rel-dependent induction of A1 transcription is required to protect B cells from antigen receptor ligation-induced apoptosis. Genes Dev 1999; 13:400-11.

[60]Lee HH, Dadgostar H, Cheng Q, Shu J, Cheng G. NF- $\kappa$ B-mediated up-regulation of Bcl-x and Bfl1/A1 is required for CD40 survival signaling in B lymphocytes. Proc Natl Acad Sci USA 1999; 96:913641.

[61]Wang CY, Guttridge DC, Mayo MW, Baldwin AS, Jr. NF- к B induces expression of the Bcl-2 homologue A1/Bfl-1 to preferentially suppress chemotherapy-induced apoptosis. Mol Cell Biol 1999; 19:59239.

[62]Fenteany G, Standaert RF, Lane WS, Choi S, Corey EJ, Schreiber SL. Inhibition of proteasome activities and subunit-specific amino-terminal threonine modification by lactacystin. Science 1995; 268:726-31.

[63]Matsui K, Omura S, Cui H, Schauer SL, Sonenshein GE, Ju ST. Proteasome regulation of Fas ligand cytotoxicity. Eur J Immunol 1997; 27:2269-78.

[64]Schreck R, Meier B, Mannel DN, Droge W, Baeuerle PA. Dithiocarbamates as potent inhibitors of nuclear factor $\kappa$ B activation in intact cells. J Exp Med 1992; 175:1181-94.

[65] Bajpai UD, Zhang K, Teutsch M, Sen R, Wortis HH. Bruton's tyrosine kinase links the B cell receptor to nuclear factor к B activation. J Exp Med 2000; 191:1735-44.

[66]Petro JB, Rahman SM, Ballard DW, Khan WN. Bruton's tyrosine kinase is required for activation of I к B kinase and nuclear factor $\kappa$ B in response to B cell receptor engagement. J Exp Med 2000; 191: 1745-54.

[67] Yang E, Korsmeyer SJ. Molecular thanatopsis: a discourse on the BCL2 family and cell death. Blood 1996; 88:386-401.

[68] Schneider TJ, Grillot D, Foote LC, Nunez GE, Rothstein TL. Bcl-x protects primary B cells against Fasmediated apoptosis. J Immunol 1997; 159:4834-9.

[69] Zhang X, Li L, Choe J, et al. Up-regulation of Bcl-xL expression protects CD40-activated human B cells from Fas-mediated apoptosis. Cell Immunol 1996; 173:149-54.

[70] Huang DC, Hahne M, Schroeter M, et al. Activation of Fas by FasL induces apoptosis by a mechanism that cannot be blocked by Bcl-2 or Bcl-x(L). Proc Natl Acad Sci USA 1999; 96:14871-6.

[71] Zamzami N, Marchetti P, Castedo M, et al. Sequential reduction of mitochondrial transmembrane potential and generation of reactive oxygen species in early programmed cell death. J Exp Med 1995; 182:367-77.

[72] Decaudin D, Geley S, Hirsch T, et al. Bcl-2 and Bcl-XL antagonize the mitochondrial dysfunction preceding nuclear apoptosis induced by chemotherapeutic agents. Cancer Res 1997; 57:62-7.

[73] Arora AS, Jones BJ, Patel TC, Bronk SF, Gores GJ. Ceramide induces hepatocyte cell death through disruption of mitochondrial function in the rat. Hepatology 1997; 25:958-63. 
[74] Gudz TI, Tserng KY, Hoppel CL. Direct inhibition of mitochondrial respiratory chain complex III by cell-permeable ceramide. J Biol Chem 1997; 272:24154-8.

[75] Scaffidi C, Schmitz I, Zha J, Korsmeyer SJ, Krammer PH, Peter ME. Differential modulation of apoptosis sensitivity in CD95 type I and type II cells. J Biol Chem 1999; 274:22532-8.

[76] Irmler M, Thome M, Hahne M, et al. Inhibition of death receptor signals by cellular FLIP [see comments]. Nature 1997; 388:190-5.

[77\} Hu S, Vincenz C, Ni J, Gentz R, Dixit VM. I-FLICE, a novel inhibitor of tumor necrosis factor receptor1- and CD- 95-induced apoptosis. J Biol Chem 1997; 272:17255-7.

[78] Srinivasula SM, Ahmad M, Ottilie S, et al. FLAME-1, a novel FADD-like anti-apoptotic molecule that regulates Fas/TNFR1-induced apoptosis. J Biol Chem 1997; 272:18542-5.

[79] Goltsev YV, Kovalenko AV, Arnold E, Varfolomeev EE, Brodianskii VM, Wallach D. CASH, a novel caspase homologue with death effector domains. J Biol Chem 1997; 272:19641-4.

[80] Van Parijs L, Refaeli Y, Abbas AK, Baltimore D. Autoimmunity as a consequence of retrovirus-mediated expression of C-FLIP in lymphocytes. Immunity 1999; 11:763-70.

[81] Wang J, Lobito AA, Shen F, Hornung F, Winoto A, Lenardo MJ. Inhibition of Fas-mediated apoptosis by the B cell antigen receptor through c-FLIP. Eur J Immunol 2000; 30:155-63.

[82] Lin EY, Orlofsky A, Berger MS, Prystowsky MB. Characterization of A1, a novel hemopoietic-specific early-response gene with sequence similarity to bcl-2. J Immunol 1993; 151:1979-88.

[83] Krikos A, Laherty CD, Dixit VM. Transcriptional activation of the tumor necrosis factor a -inducible zinc finger protein, A20, is mediated by $\kappa$ B elements. J Biol Chem 1992; 267:17971-6.

[84] Takayama S, Sato T, Krajewski S, et al. Cloning and functional analysis of BAG-1: a novel Bcl-2-binding protein with anti-cell death activity. Cell 1995; 80:279-84.

[85] Pegoraro L, Palumbo A, Erikson J, et al. A 14; 18 and an 8; 14 chromosome translocation in a cell line derived from an acute B-cell leukemia. Proc Natl Acad Sci USA 1984; 81:7166-70.

[86] Hockenbery D, Nunez G, Milliman C, Schreiber RD, Korsmeyer SJ. Bcl-2 is an inner mitochondrial membrane protein that blocks programmed cell death. Nature 1990; 348:334-6.

[87] Rothe M, Pan MG, Henzel WJ, Ayres TM, Goeddel DV. The TNFR2-TRAF signaling complex contains two novel proteins related to baculoviral inhibitor of apoptosis proteins. Cell 1995; 83:1243-52.

[88] Wang L, Miura M, Bergeron L, Zhu H, Yuan J. Ich-1, an Ice/ced-3-related gene, encodes both positive and negative regulators of programmed cell death. Cell 1994; 78:739-50.

[89] Wu MX, Ao Z, Prasad KV, Wu R, Schlossman SF. IEX-1L, an apoptosis inhibitor involved in NF$\$ \backslash$ kappa $\$$ B-mediated cell survival. Science 1998; 281:998-1001.

[90] Ambrosini G, Adida C, Altieri DC. A novel anti-apoptosis gene, survivin, expressed in cancer and lymphoma. Nat Med 1997; 3:917-21.

[91] Liang P, Pardee AB. Differential display of eukaryotic messenger RNA by means of the polymerase chain reaction [see comments]. Science 1992; 257:967-71.

[92] Mizuguchi J, Ji YY, Nakabayaschi H, et al. Protein kinase C activation blocks anti-IgM-mediated signaling BAL17 B lymphoma cells. J Immunol 1987; 139:1054-9.

[93] Tewari M, Quan LT, O'Rourke K, et al. Yama/CPP32 beta, a mammalian homolog of CED-3, is a CrmAinhibitable protease that cleaves the death substrate poly (ADP-ribose) polymerase. Cell 1995; 81:8019.

[94] Nicholson DW, Ali A, Thornberry NA, et al. Identification and inhibition of the ICE/CED-3 protease necessary for mammalian apoptosis [see comments]. Nature 1995; 376:37-43.

[95] Lennon G, Auffray C, Polymeropoulos M, Soares MB. The I.M.A.G.E. Consortium: an integrated molecular analysis of genomes and their expression. Genomics 1996; 33:151-2.

[96] Zhong X, Schneider TJ, Donohoe TJ, Rothstein TL. A novel isoform of Fas Apoptosis Inhibitory Molecule (FAIM)--cloning, genomic organization, alternative splicing and restricted expression. Submitted 2000;

[97] aimondi SC, Dube ID, Valentine MB, et al. Clinicopathologic manifestations and breakpoints of the $t$ 
Inducible Fas-resistance in B cells

$(3 ; 5)$ in patients with acute nonlymphocytic leukemia. Leukemia 1989; 3:42-7.

[98] Dierlamm J, Rosenberg C, Stul M, et al. Characteristic pattern of chromosomal gains and losses in marginal zone B cell lymphoma detected by comparative genomic hybridization. Leukemia 1997; 11: 747-58

[99] Petersen I, Bujard M, Petersen S, et al. Patterns of chromosomal imbalances in adenocarcinoma and squamous cell carcinoma of the lung. Cancer Res 1997; 57:2331-5.

[100] Djerbi M, Screpanti V, Catrina AI, Bogen B, Biberfeld P, Grandien A. The inhibitor of death receptor signaling, FLICE-inhibitory protein defines a new class of tumor progression factors [see comments]. J Exp Med 1999; 190:1025-32.

[101] Medema JP, de Jong J, van Hall T, Melief CJ, Offringa R. Immune escape of tumors in vivo by expression of cellular FLICE- inhibitory protein [see comments]. J Exp Med 1999; 190:1033-8.

[102] Balvay L, Libri D, Fiszman MY. Pre-mRNA secondary structure and the regulation of splicing. Bioessays 1993; 15:165-9.

[103] Cavalier-Smith T. Intron phylogeny: a new hypothesis. Trends Genet 1991; 7:145-8.

[104] Palmer JD, Logsdon JM, Jr. The recent origins of introns. Curr Opin Genet Dev 1991; 1:470-7.

[105] Lomedico P, Rosenthal N, Efstratidadis A, Gilbert W, Kolodner R, Tizard R. The structure and evolution of the two nonallelic rat preproinsulin genes. Cell 1979; 18:545-58.

[106] Li WH, Tanimura M, Luo CC, Datta S, Chan L. The apolipoprotein multigene family: biosynthesis, structure, structure-function relationships, and evolution. J Lipid Res 1988; 29:245-71.

[107] Frugoli JA, McPeek MA, Thomas TL, McClung CR. Intron loss and gain during evolution of the catalase gene family in angiosperms. Genetics 1998; 149:355-65.

[108] Lane P, Traunecker A, Hubele S, Inui S, Lanzavecchia A, Gray D. Activated human T cells expre ss a ligand for the human B cell- associated antigen CD40 which participates in T cell- dependent activation of B lymphocytes. Eur J Immunol 1992; 22:2573-8.

[109] Noelle RJ, Roy M, Shepherd DM, Stamenkovic I, Ledbetter JA, Aruffo A. A 39- kDa protein on activated helper T cells binds CD40 and transduces the signal for cognate activation of B cells. Proc Natl Acad Sci USA 1992; 89:6550-4.

[110] Armitage RJ, Fanslow WC, Strockbine L, et al. Molecular and biological characterization of a murine ligand for CD40. Nature 1992; 357:80-2.

[111] Ju ST, Panka DJ, Cui H, et al. Fas(CD95)/FasL interactions required for programmed cell death after T-cell activation [see comments]. Nature 1995; 373:444-8.

[112] Brunner T, Mogil RJ, LaFace D, et al. Cell-autonomous Fas (CD95)/Fas-ligand interaction mediates activation-induced apoptosis in T-cell hybridomas [see comments]. Nature 1995; 373:441-4.

[113] Dhein J, Walczak H, Baumler C, Debatin KM, Krammer PH. Autocrine T-cell suicide mediated by APO1/(Fas/CD95) [see comments]. Nature 1995; 373:438-41.

[114] Alderson MR, Tough TW, Davis-Smith T, et al. Fas ligand mediates activation-induced cell death in human T lymphocytes. J Exp Med 1995; 181:71-7.

[115] Ozdemirli M, El-Khatib M, Foote LC, et al. Fas (CD95)/Fas ligand interactions regulate antigenspecific, major histocompatibility complex-restricted T/B cell proliferative responses. Eur J Immunol 1996; 26:415-9.

[116] Wang JKM, Ju ST, Marshak-Rothstein A. Protection of T cells from activation-induced cell death by Fas + B cells. Eur J Immunol 2000; in press.

[117] Shlomchik MJ, Marshak-Rothstein A, Wolfowicz CB, Rothstein TL, Weigert MG. The role of clonal selection and somatic mutation in autoimmunity. Nature 1987; 328:805-11.

[118] Wolfowicz CB, Sakorafas P, Rothstein TL, Marshak-Rothstein A. Oligoclonality of rheumatoid factors arising spontaneously in lor/ lpr mice. Clin Immunol Immunopathol 1988; 46:382-95.

[119] Shlomchik M, Mascelli M, Shan H, et al. Anti-DNA antibodies from autoimmune mice arise by clonal expansion and somatic mutation. J Exp Med 1990; 171:265-92.

[120] Rathmell JC, Cooke MP, Ho WY, et al. CD95 (Fas)-dependent elimination of self-reactive B cells upon 
Rothstein TL

interaction with CD4+ T cells. Nature 1995; 376:181-4.

[121] Wang H, Shlomchik MJ. Autoantigen-specific B cell activation in Fas-deficient rheumatoid factor immunoglobulin transgenic mice. J Exp Med 1999; 190:639-49.

[122] Cooke MP, Heath AW, Shokat KM, et al. Immunoglobulin signal transduction guides the specificity of B cell-T cell interactions and is blocked in tolerant self-reactive B cells. J Exp Med 1994; 179:42538.

[123] Eris JM, Basten A, Brink R, Doherty K, Kehry MR, Hodgkin PD. Anergic self-reactive B cells present self antigen and respond normally to CD40-dependent T-cell signals but are defective in antigenreceptor-mediated functions. Proc Natl Acad Sci USA 1994; 91:4392-6.

[124] Ho WY, Cooke MP, Goodnow CC, Davis MM. Resting and anergic B cells are defective in CD28dependent costimulation of naive CD4+ T cells. J Exp Med 1994; 179:1539-49.

[125] Burstein HJ, Tepper RI, Leder P, Abbas AK. Humoral immune functions in IL-4 transgenic mice. J Immunol 1991; 147:2950-6.

[126] Erb KJ, Ruger B, von Brevern M, Ryffel B, Schimpl A, Rivett K. Constitutive expression of interleukin (IL)-4 \{ $\backslash$ sl in vivo $\}$ causes autoimmune- type disorders in mice. J Exp Med 1997; 185:329-39.

[127] Rathmell JC, Fournier S, Weintraub BC, Allison JP, Goodnow CC. Repression of B7.2 on self-reactive $\mathrm{B}$ cells is essential to prevent proliferation and allow Fas-mediated deletion by CD4(+) T cells. J Exp Med 1998; 188:651-9.

[128] DiPiro JT, Howdieshell TR, Goddard JK, Callaway DB, Hamilton RG, Mansberger AR, Jr. Association of interleukin-4 plasma levels with traumatic injury and clinical course. Arch Surg 1995; 130:115962; discussion 1162-3.

[129] Klas C, Debatin KM, Jonker RR, Krammer PH. Activation interferes with the APO-1 pathway in mature human T cells. Int Immunol 1993; 5:625-30.

[130] Refaeli Y, Van Parijs L, London CA, Tschopp J, Abbas AK. Biochemical mechanisms of IL-2-regulated Fas-mediated T cell apoptosis. Immunity 1998; 8:615-23.

[131] Broome HE, Dargan CM, Krajewski S, Reed JC. Expression of Bcl-2, Bcl-x, and Bax after T cell activation and IL-2 withdrawal. J Immunol 1995; 155:2311-7.

[132] Peter ME, Kischkel FC, Scheuerpflug CG, Medema JP, Debatin KM, Krammer PH. Resistance of cultured peripheral T cells towards activation-induced cell death involves a lack of recruitment of FLICE (MACH/caspase 8) to the CD95 death-inducing signaling complex. Eur J Immunol 1997; 27: 1207-12.

[133] Scaffidi C, Schmitz I, Krammer PH, Peter ME. The role of c-FLIP in modulation of CD95-induced apoptosis. J Biol Chem 1999; 274:1541-8.

[134] Miethke T, Vabulas R, Bittlingmaier R, Heeg K, Wagner H. Mechanisms of peripheral T cell deletion: anergized $\mathrm{T}$ cells are Fas resistant but undergo proliferation-associated apoptosis. Eur J Immunol 1996; 26:1459-67.

[135] Boussiotis VA, Lee BJ, Freeman GJ, Gribben JG, Nadler LM. Induction of T cell clonal anergy results in resistance, whereas CD28- mediated costimulation primes for susceptibility to Fas- and Baxmediated programmed cell death. J Immunol 1997; 159:3156-67.

[136] Zhang X, Brunner T, Carter L, et al. Unequal death in T helper cell (Th)1 and Th2 effectors: Th1, but not Th2, effectors undergo rapid Fas/FasL-mediated apoptosis. J Exp Med 1997; 185:1837-49.

[137] Varadhachary AS, Perdow SN, Hu C, Ramanarayanan M, Salgame P. Differential ability of T cell subsets to undergo activation-induced cell death. Proc Natl Acad Sci USA 1997; 94:5778-83.

[138] Di Somma MM, Somma F, Montani MS, Mangiacasale R, Cundari E, Piccolella E. TCR engagement regulates differential responsiveness of human memory $\mathrm{T}$ cells to Fas (CD95)-mediated apoptosis. J Immunol 1999; 162:3851-8.

[139] Inaba M, Kurasawa K, Mamura M, Kumano K, Saito Y, Iwamoto I. Primed T cells are more resistant to Fas-mediated activation-induced cell death than naive T cells. J Immunol 1999; 163:1315-20.

[140] Panayiotidis P, Ganeshaguru K, Foroni L, Hoffbrand AV. Expression and function of the FAS antigen 
Inducible Fas-resistance in B cells

in B chronic lymphocytic leukemia and hairy cell leukemia. Leukemia 1995; 9:1227-32.

[141] Xerri L, Devilard E, Hassoun J, Haddad P, Birg F. Malignant and reactive cells from human lymphomas frequently express Fas ligand but display a different sensitivity to Fas-mediated apoptosis. Leukemia 1997; 11:1868-77.

[142] Plumas J, Jacob MC, Chaperot L, Molens JP, Sotto JJ, Bensa JC. Tumor B cells from non-Hodgkin's lymphoma are resistant to CD95 (Fas/Apo-1)-mediated apoptosis. Blood 1998; 91:2875-85.

[143] Xerri L, Devilard E, Bouabdallah R, Stoppa AM, Hassoun J, Birg F. FADD expression and caspase activation in B-cell lymphomas resistant to Fas-mediated apoptosis. Br J Haematol 1999; 106:65261.

[144] Owen-Schaub LB, Radinsky R, Kruzel E, Berry K, Yonehara S. Anti-Fas on nonhematopoietic tumors: levels of Fas/APO-1 and bcl-2 are not predictive of biological responsiveness. Cancer Res 1994; 54: 1580-6.

[145] Natoli G, Ianni A, Costanzo A, et al. Resistance to Fas-mediated apoptosis in human hepatoma cells. Oncogene 1995; 11:1157-64.

[146] Keane MM, Ettenberg SA, Lowrey GA, Russell EK, Lipkowitz S. Fas expression and function in normal and malignant breast cell lines. Cancer Res 1996; 56:4791-8.

[147] Ungefroren H, Voss M, Jansen M, et al. Human pancreatic adenocarcinomas express Fas and Fas ligand yet are resistant to Fas-mediated apoptosis. Cancer Res 1998; 58:1741-9.

[148] Hedlund TE, Duke RC, Schleicher MS, Miller GJ. Fas-mediated apoptosis in seven human prostate cancer cell lines: correlation with tumor stage. Prostate 1998; 36:92-101.

[149] Baldwin RL, Tran H, Karlan BY. Primary ovarian cancer cultures are resistant to Fas-mediated apoptosis. Gynecol Oncol 1999; 74:265-71.

[150] Peng SL, Robert ME, Hayday AC, Craft J. A tumor-suppressor function for Fas (CD95) revealed in T cell-deficient mice. J Exp Med 1996; 184:1149-54.

[151] Traver D, Akashi K, Weissman IL, Lagasse E. Mice defective in two apoptosis pathways in the myeloid lineage develop acute myeloblastic leukemia. Immunity 1998; 9:47-57.

[152] Davidson WF, Giese T, Fredrickson TN. Spontaneous development of plasmacytoid tumors in mice with defective Fas-Fas ligand interactions. J Exp Med 1998; 187:1825-38.

[153] Owen-Schaub LB, van Golen KL, Hill LL, Price JE. Fas and Fas ligand interactions suppress melanoma lung metastasis. J Exp Med 1998; 188:1717-23.

[154] Furman RR, Asgary Z, Mascarenhas JO, Liou HC, Schattner EJ. Modulation of NF- $\kappa$ B activity and apoptosis in chronic lymphocytic leukemia B cells. J Immunol 2000; 164:2200-6.

[155] Ugurel S, Seiter S, Rappl G, Stark A, Tilgen W, Reinhold U. Heterogenous susceptibility to CD95induced apoptosis in melanoma cells correlates with bcl-2 and bcl-x expression and is sensitive to modulation by interferon- $\gamma$. Int J Cancer 1999; 82:727-36. 